\title{
Periodismo digital y paz: ensayo sobre La Silla Vacía, Colombia
}

\section{Digital journalism and Peacemaking: an essay about La Silla Vacía, Colombia}

DOI: https://doi.org/10.29166/tyc.v1i20.2164

\section{Sandra Sánchez López}

Es profesora del Centro de Estudios en Periodismo, Ceper, de la Facultad de Artes y Humanidades de la Universidad de los Andes, Colombia. Es historiadora y analista de medios, con énfasis en categorías de poder como la clase y el género.

Correo: ssanchez@uniandes.edu.co

\section{Silvia Gómez Montero}

Es asesora de la Subdirección Académica de la Escuela Superior de Administración Pública, Colombia. Cursa actualmente el doctorado en Ciencias Humanas y Sociales en el Centro de Estudios Sociales de la Facultad de Ciencias Humanas de la Universiad Nacional de Colombia, sede Bogotá.

Correo: sm.gomez10@uniandes.edu.co

\section{Resumen}

Aquí consideramos el ejercicio de La Silla Vacía (Colombia), medio de vanguardia en cubrimiento político, durante la fase final de preparación para el Plebiscito de los acuerdos de paz colombianos (2016), cuando se discutía un nuevo modelo de nación que pronto entró en declive. Esta exploración revela que La Silla implementó estrategias de información con las que materializó varios de sus propósitos originarios para sostener una democracia sana desde el periodismo. Sin embargo, también muestra que se vio retada: los resultados de la votación del Plebiscito confrontó su confianza en un paradigma racional.

Palabras clave: periodismo digital, plebiscito, paz, democracia, La Silla Vacía.

\section{Abstract}

Here, we consider the work of La Silla Vacía (Colombia), a vanguard means of political coverage, during the final phase of preparation for the Plebiscite of the Colombian peace agreements (2016), when a new model of nation was debated that soon entered into slope. This exploration reveals that La Silla, implemented information strategies with that it materialized several of its original purposes to sustain a healthy democracy from journalism. However, it also shows that it was challenged: the Plebiscite vote results confronted its confidence in a rational paradigm.

Keywords: digital journalism, plebiscite, peace, democracy, La Silla Vacía. 
La Silla Vacía cumplió una década el pasado 2019. Nació como un combatiente, cuyo objetivo era dinamizar el escenario restringido y monótono de los medios en la Colombia de entonces. Desde el inicio, su apuesta ha consistido en hacer periodismo independiente, aprovechando por lo menos dos las bondades del espacio digital: interactividad e innovación en las formas de contar. Para sus creadoras, Juanita León y Olga Lucía Lozano, "ningún medio ofrece tantas posibilidades narrativas y de construcción de comunidad como internet" (León \& Lozano, 2013, p. 5). Por lo mismo, fue allí donde decidieron ubicar su periodismo hace 10 años. León y Lozano concibieron su proyecto como un laboratorio permanente, desligado de los grandes medios del país, quienes aún hoy tardan en incursionar de manera propositiva en el mundo digital periodístico. Esos propósitos de La Silla se mantuvieron vigentes durante su cubrimiento de los diálogos de paz y la fase de preparación para el Plebiscito colombiano de octubre de 2016.

Aquí ofrecemos una mirada a ese cubrimiento, pasados ya tres años desde la votación, pero aún en medio de la discusión sobre el paradero final de la paz, cuando bajo el gobierno del actual presidente, Iván Duque, el país vive un escalamiento definitivo del conflicto. Lo que hizo La Silla en tiempos del Plebiscito es hoy prototipo (im)perfecto del oficio en la región latinoamericana para continuar con las tareas de cubrir paz y crisis, polarización política y definición de los cursos de una nación.

¿Cómo fue el cubrimiento del Plebiscito por parte de La Silla, teniendo en cuenta su compromiso de contrapoder y de rastreo de la alta política? ¿De qué ma- nera se exhibió su naturaleza de nativo digital y sus apuestas en términos de diseño y narrativas en red, apoyados en la tecnología digital? Estas son las preguntas rectoras aquí, unas que pretenden facilitar posteriores discusiones sobre cómo y hasta dónde los nativos digitales latinoamericanos, en especial en coyunturas de explosión de fuerzas de poder como la del pasado Plebiscito colombiano, operan (o no) como base y proponentes de una sociedad incluyente, participativa y equilibrada desde el oficio periodístico (Morelo, Castrillón \& Behar, 2014). En últimas, buscamos re-descubrir, desde la revisión del caso del cubrimiento de un tan exigente tema como el de la paz colombiana, claves preliminares para eventualmente, en comunidad, volver a pensar los atributos de los nativos digitales, en materia de apropiación y ejercicio de prácticas espejo de democracia.

\section{La Silla en contexto}

El impulso de fundar La Silla fue parte del devenir mediático regional. Para el momento en que este medio surgía, otros latinoamericanos como Ciper y The Clinic (Chile); Confidencial (Nicaragua); El Faro (El Salvador); IDL-Reporteros (Perú); Plaza Pública (Guatemala); Puercoespín (Argentina); Animal Político (México); y Agencia Pública (Brasil) también se situaban a la vanguardia de la crítica y de la creación de un periodismo nativo digital en América Latina. El compromiso de todo ellos, como el de La Silla, fue integrar a su quehacer fórmulas de financiación para garantizar su independencia de los poderes mediáticos, a disposición de persistentes exigencias externas, 
típicamente empresariales. Se concentraron en el core de la noticia: la política institucional, la de quienes toman las decisiones en el poder, la de la autoridad que influye en la vida de todos (León \& Lozano, 2013). Con este enfoque, proyectaron su seguimiento a los poderosos y han sostenido su convicción contar la "tras-escena" de las decisiones que definen el rumbo de los países para, así, establecer una contraparte a ese poder, desde las historias periodísticas digitales (Moreno et al., 2013). Estimaron que su propuesta constituía una renovación genuina frente a lo que veían como el trajinado entorno mediático impreso y dependiente de los intereses de las élites $^{1}$. Así, se volvían contestatarios frente a la gran prensa, mostrando que ésta había negociado por mucho tiempo su autonomía y había quebrantado las reglas de un juego limpio en la producción de información ${ }^{2}$.

Además de ese diagnóstico de los nativos digitales sobre la trayectoria de la prensa latinoamericana, parecía, en el caso específico de Colombia, que un periodismo del talante del de La Silla era urgente por la historia misma del país. Es sabido que el conflicto colombiano es uno de los más longevos en el contexto regional, con múltiples sectores involucrados que apoyan y reproducen abierta o veladamente la crisis. Las disputas sangrien- tas por la tierra, la colonización de zonas de fronteras sin pautas estatales y la centralización del poder, encarnada en una política sectaria y sumada al gamonalismo y al clientelismo de zonas periféricas, son motores primigenios que los historiadores han identificado desde hace mucho como causas contundentes de la guerra en el país (Roldán, 2002; Appelbaum, 2003; Karl, 2017). Con prácticas de ausencia estatal y de corrupción y faccionalización política y social inició el conflicto, y todas ellas están reafirmadas y aumentando hoy sin excepción alguna, luego de los visos de paz recientes.

El narcotráfico no puede excluirse de este cuadro en descripción. Éste acentuó todas esas formas de violencia primigenias y, entretejido con las guerrillas y las bandas criminales urbanas y rurales, en convivencia con el paramilitarismo, terminó por perpetuar la inestabilidad social, los desplazamientos y las muertes en el país. La década de 1990 fue la de las capturas de los capos más conocidos de la droga colombiana: Pablo Escobar y los hermanos Orejuela, Gilberto y Miguel. Escobar terminó asesinado. Los Orejuela cumplen sentencias de 30 años en cárceles estadounidenses. En esos años 90, la erradicación del narcotráfico se pensaba como asunto policial y jurídico. Entonces, la esperanza de ponerle fin significó encerrar o matar a sus líderes.

1 Como lo han anotado Becerra y Mastrini (2010), la fórmula de la tenencia de medios se agota en pocos nombres que se repiten en otros sectores de la economía, dando paso a la centralización de medios: la información la financian unos cuantos que, a su vez, financian los peldaños más prominentes de otras industrias y negocios de sus sociedades. Aquí sucede la concentración: se consume una reducida cuota de contenidos -justamente aquellos que publicitan y benefician el entorno de propiedad de sus dueños.

2 En Colombia, los grandes medios, El Espectador, El Tiempo, Caracol y RCN, son propiedad del Grupo Santo Domingo, Luis Carlos Sarmiento y Ardila Lulle, respectivamente, quienes también son dueños de las más grandes empresas de servicios, inversiones y construcción del país. Frente a esto, el ámbito digital ha implicado para La Silla su autonomía financiera respecto de los conglomerados vigentes. También de ello ha resultado la libertad para un periodismo despojado de las exigencias derivadas, precisamente, de las prevalecientes concentración y centralización. 
Pero ni las muertes de los capos ni su encarcelamiento cerró el negocio. El narcotráfico continuó, tanto que hoy los asesinatos crecientes de líderes sociales en zonas rurales están asociados a la lucha por recuperar las vías más fructíferas del tráfico de drogas para exportación. Para noviembre de 2018, a solo tres meses del posicionamiento de Duque, las muertes de estos líderes ascendían a más de 200 ("Van 226 líderes", 2018). Todas ellas se presentaron y siguen presentándose en lugares que habían superado de manera relativa y momentánea la violencia, pasados los diálogos con la guerrilla FARC. Como también es conocido, a todo esto se ha sumado la violencia rutinaria de la cotidianidad, en clave de racismo, clasismo y sexismo. Solo en febrero de 2019, mataron a 19 mujeres en el país (Avella-Bermúdez, 2019) y la cuenta aumenta para 2020.

A este contexto al que responde la propuesta periodística de La Silla se añade el obligado tema del gobierno de Álvaro Uribe (2002-2010). Es clave recordar que Uribe, luego de ser presidente, se convirtió en senador y que, en las pasadas elecciones de 2018, lo fue por segunda vez, siendo el congresista más votado. Actualmente, su autoridad se mantiene por cuenta de las urnas. Como presidente, impuso "mano dura" a las guerrillas, en particular a la misma de los pasados diálogos, la FARC. Además, y para frenar críticas sobre posibles nexos del gobierno con el paramilitarismo en su lucha contraguerrilla, Uribe tramitó también medidas para aliviar el paramilitarismo y se extraditaron a varios de sus líderes, entre ellos a Salvatore Mancuso y Diego Fernando Murillo, conocido como Don Berna. Con esto parecía encararse un problema casi tan longevo como el de la guerrilla: el de la defensa militar a título propio, fuera del aparato estatal.

Entonces, era casi el final del gobierno de Uribe cuando La Silla empezó, y como lo asegura Daniel Coronell (2011), uno de los periodistas y columnistas más visibles del país, los medios permanecían adeptos a las consignas de patriotismo de Uribe, sin que se le disputara nada al presidente. En este punto, La Silla apareció con la fuerza de sus propósitos de un mejor periodismo. Pronto llegaría la era de Juan Manuel Santos (2010-2018) y el medio se enfrentaría a retos informativos grandes frente a la trayectoria de los conflictos nacionales.

De manera importante, la época de Santos fue la de los diálogos en La Habana, Cuba, y las negociaciones de unos acuerdos que polarizaron una vez más a los colombianos ${ }^{3}$ : mientras algunos mantenían la esperanza de encontrar la paz a través de las negociaciones con la guerrilla, otros se resistieron con vehemencia. Dentro de esa franja que aún hoy se resiste está una porción importante de la ciudadanía, que en las urnas del Plebiscito del 2 de octubre de 2016 -por mayoría de los votantes y de una manera que ni las encuestas, ni los expertos, ni los medios vieron venir-, decidió no avalar los acuerdos como estaban (Abad-Faciolince, 2016). Además, el tema de la paz o la imposibilidad de ésta persisten, y eso es

3 Para información más detallada del proceso de La Habana, consultar: http://www.altocomisionadoparalapaz.gov.co/mesadeconversaciones/index.html 
algo que La Silla, en su enfoque de poder, ha tenido que cubrir de cerca, lo que empezó a hacer durante los diálogos y el tiempo previo a la votación.

Desde ese 2 de octubre, la crisis en torno a la paz es diaria: la implementación de los acuerdos, ya con casi todos sus elementos desajustados, ha encontrado un sin fin de tropiezos; la Jurisdicción Especial para la Paz, JEP, arrancó, pero de manera muy lenta; la corrupción ha tenido a senadores, gobernadores y otros miembros de las elites políticas en batallas jurídicas que se ratifican día con día; las disputas por los corredores de la droga están en vigor; y las promesas de Duque a Trump sobre la lucha antidroga en su visita de 2019 a los Estados Unidos dejó a los colombianos en las mismas: erradicación de cultivos ilícitos sin soluciones de sustitución para los campesinos y las disputas por la tierra vueltas sangre. La paz y la guerra y las disputas políticas en torno a estas, como visión de construcción de nación, siguen en la agenda central de cubrimiento de $L a$ Silla, tal como en 2016 para el momento del Plebiscito.

\section{Estrategias de participación digital}

Con el surgimiento de internet, se abrió el espacio para la participación activa en la discusión sobre el acontecer de la arena política. Esto tuvo consecuencias en la concepción de unos valores de inclusión como elemento clave de la política de medios, exacerbada por vía de las prácticas periodísticas en el espacio digital (Piscitelli, 2005). Por eso, de acuerdo con Castells, "de la comunicación de masas dirigida a una audiencia, hemos pasado a una audiencia activa que forja su significado comparando su experiencia con los flujos unidireccionales de la información que recibe" (Castells, 2009, p. 184). Ampliando esto, Fogel (2007) afirma que con las tecnologías inventadas por Gutemberg y Marconi el individuo se definía frente al contenido de los medios a partir de dos respuestas: la identificación o el rechazo. Internet añadió una tercera: ser el creador, promotor de la conciencia colectiva, al comportarse no como receptor, sino también como emisor de contenidos. En el marco de lo digital, el individuo alcanza, así, la posibilidad de co-definir el sistema de circulación de la información que le importa. La red parece, entonces, un espacio donde la confluencia de agentes humanos es natural a las particularidades de la conectividad digital.

En este contexto, La Silla puso en práctica durante su cubrimiento del Plebiscito varias estrategias que aprovecharon la arquitectura digital para el desarrollo de productos periodísticos que impulsaron principios de pluralismo, diálogo, controversia y consenso ciudadanos. Estas estrategias se potencializarían al conjugarse con los principios de interactividad y conectividad que La Silla mantuvo para informar a la ciudadanía de cara a las votaciones por el Sí o el No de los acuerdos con las FARC. El medio se apropió de lleno de los elementos de la red para ponerlos a funcionar y conectar a los ciudadanos en torno a lo que La Silla misma proponía en la agenda noticiosa de paz.

Lo primero que hizo el medio en esta fase de ejercicios de participación fue trabajar por mantener la habitual conjunción de públicos que podían tomar decisiones políticas en las urnas, a pesar de sus diferencias generacionales y su nivel 
de alfabetización digital. Así, en los meses previos al Plebiscito, la interacción de públicos en el medio estuvo protagonizada por las audiencias de entre 25 y 34 años, quienes son los más numerosos $(36,6 \%)$, seguidos de los de 35-45 años (19,3\%), los de 55-64 (16,2\%) y, por último, los de 4554 (11,6\%). Los públicos de menor interacción en esta puerta de participación de La Silla fueron, por una parte, los millenials (usuarios-lectores de 18-24 años y que suman el 8,5\%) y, por otra, los más longevos (mayores de 65 años de edad y que equivalen al $7,8 \%$ ). Los millenials apenas se estaban familiarizando con los asuntos políticos y agendas de poder en el periodismo, obteniendo información sobre paz prioritariamente de redes sociales, cuando lo hacían. Los longevos se encontraban insertados en el consumo de medios en papel y menos digitales, consultando información sobre el Plebiscito prioritariamente en el periodismo impreso (Bonilla, et.al., 2012).

En la Figura 1, las letras indican diferencias significativas (con $\mathrm{p} \leq 0.005$ ), revelando la proximidad entre las audiencias que más interactuaron en el tiempo estudiado - las de las audiencias con edades intermedias (25-64 años)- y las menos involucradas -las de los extremos en edades (18-24 y +65 años) ${ }^{4}$. La gráfica muestra que, en efecto, los públicos activos durante el periodo cubierto mantuvie- ron una proximidad y convergencia en la navegación de la información producida por el medio, tal como La Silla se lo proponía, para generar un ambiente de diálogo e integración en torno a los contenidos sobre la paz. Así, todas estas franjas de edades hicieron parte del target participativo del medio, aunque algunas mostraran más empatía que otras frente a las historias que se publicaban ${ }^{5}$.

\section{Figura 1. Edades de los lectores-usuarios del $30 \%$ de las cien historias más leídas en La Silla entre junio y octubre de 2016.}

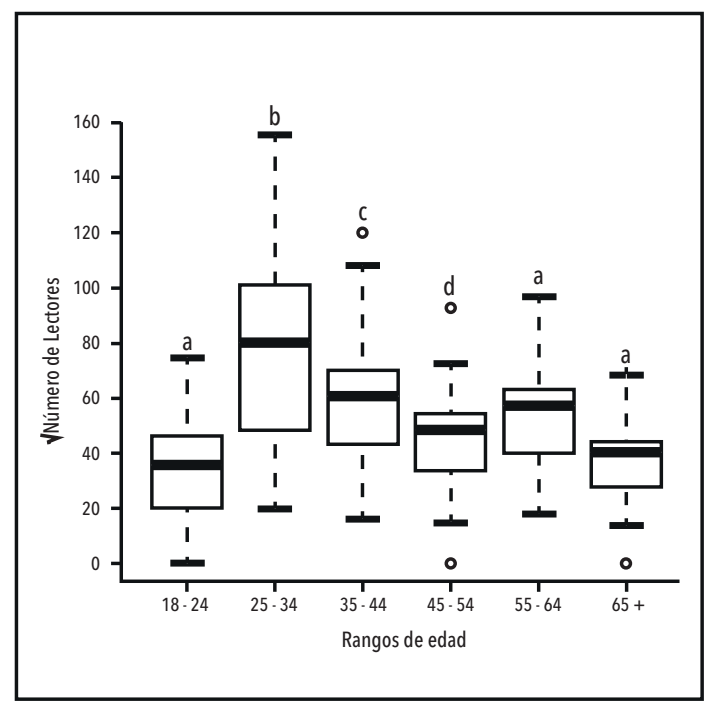

Fuente: elaboración propia y supervisión de Lina María Aragón Baquero, especialista en R

4 Para esta medición estadística, se utilizó el programa estadístico R (R Development Core Team, 2008) y el paquete lme4 (Bates et al., 2015). Se aplicó raíz cuadrada a los valores registrados en la base de datos levantada, luego de evaluar su normalidad con ShapiroWilk. La significancia estadística se determinó, para la mayoría, con un p<0.05, para el estudio de números.

5 La revisión de la interactividad, la convergencia y la personalización se plantea teniendo en cuenta las variables que los análisis del tráfico de las historias del medio registran de manera sobresaliente: usuarios-lectores; sexo, edad y región de habitación; niveles de educación; y asignación por sectores socioeconómicos. La consulta inicial de estos datos se hizo entre octubre y diciembre de 2016, por proximidad al cubrimiento, y se corroboró entre octubre y diciembre de 2017 y los mismos meses de 2018 y 2019. 
En una segunda estrategia de apertura y búsqueda de participación, La Silla puso en funcionamiento el cubrimiento de la paz y el Plebiscito en el espacio de sus llamadas patas de la silla, secciones que plantearon la expansión de su ejercicio periodístico a las regiones del país para, así, descentralizar el cubrimiento de la capital, Bogotá. Para el momento del Plebiscito, las patas de La Silla eran cuatro: Caribe, Santander, Pacífico y Sur. Ahora se han sumado otras dos: Paisa y Cachaca. Los datos muestran que las dos primeras, vigentes para el periodo de interés, registraron 127.862 visitas en ese momento. Para las dos últimas, la Pacífico y Sur, las cifras eran aún inexistentes para cuando se inició este análisis. El escenario digital del medio favoreció esta expansión rápida y eficaz hacia las regiones. A su vez, esta expansión incentivó de manera importante el diálogo entre el centro y las zonas aledañas, sobre todo en un momento de coyuntura como la del
Plebiscito, donde las decisiones de las urnas afectarían a todo el largo y ancho del país.

La Silla hablaba de "estirar sus patas" en función de una de sus convicciones: "que el país es sobre todo sus regiones, y que contar esas regiones requiere conocerlas y entenderlas bien" ("Nace nuestra primera pata regional”, 2015). Para el período de muestra, esto supuso poner en circulación fuera de la capital la información sobre los acuerdos y el Plebiscito. Este fue un paso significativo hacia la descentralización de los contenidos periodísticos sobre el tema de paz, una evidencia de la intención de pluralismo e inclusión de los asuntos regionales en el debate y la discusión sobre lo público y el ejercicio de poder, concurriendo todo en el espacio digital.

La Figura 2 ilustra la relación de consultas de usuarios-lectores por región de La Silla Caribe y La Silla Santander, entre junio y octubre de 2016. Los datos

Figura 2. Relación de consultas de usuarios-lectores por región de La Silla Caribe y La Silla Santander, entre junio y octubre de 2016.

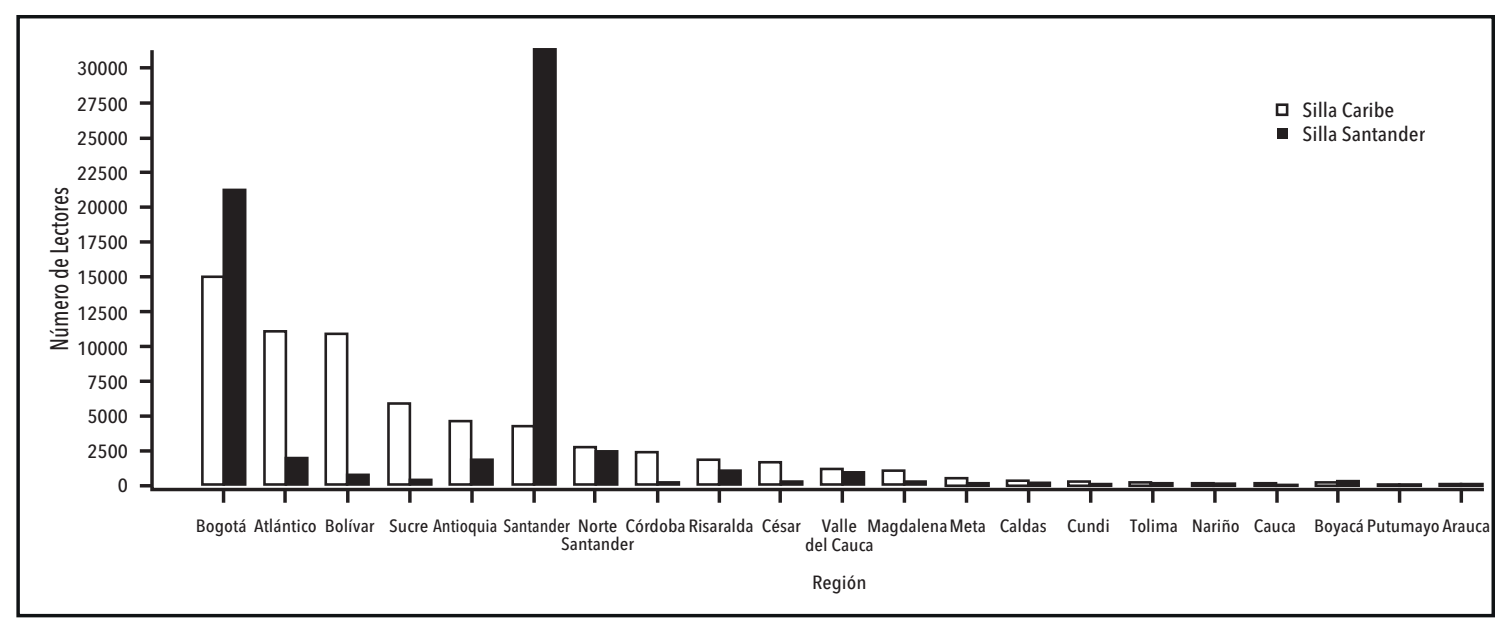

Fuente: elaboración propia y supervisión de Lina María Aragón Baquero, especialista en R. 
que grafica hacen explícito que si bien Bogotá, como centro de poder nacional mantuvo el liderazgo político y de circulación de información, las audiencias proyectadas para la lectura sobre las territorialidades contempladas en $\mathrm{LaCA}$ ribe y La Santander cumplieron con el consumo y la identificación con los contenidos que le son más próximos. Tanto caribeños como santandereanos y los habitantes de sus regiones de influencia estuvieron activos en la recepción, consulta y demanda de contenidos sobre los acuerdos y el Plebiscito, así como sobre sus implicaciones en sus contextos locales, más allá del puro epicentro del poder.

Una tercera y muy importante estrategia de información que significó un esfuerzo por conectar a la ciudadanía con asuntos del proceso de paz y del posterior Plebiscito es la apuesta interactiva de la sección "Plebiscito. Todo lo que necesita saber para votar por el sí o por el no”. Esta fue una herramienta narrativa pedagógica que se dispuso para enriquecer las posibilidades de acercamiento de las audiencias a los contenidos de los acuerdos y sus consecuencias políticas, sociales y económicas. "Plebiscito" tuvo, entonces, cinco subsecciones enteramente nuevas en $L a$ Silla, creadas para el tema específico de paz: “Test para votar”, “Así es el acuerdo", "El acuerdo explicado", "Debates" y "Preguntas”. Además, contó con tres subsecciones ya existentes, pero señaladas y alimentadas para información particular sobre el Plebiscito: "Quién es quién", "Detector de mentiras" y "La red de paz". Con textos, gráficas distribuidas por temas y convergencias, convenciones visuales e infografías, tests con resultados descriptivos y mapeo de redes y nodos de influencia, todos los elementos de
"Plebiscito" pretendieron traducir los acuerdos de suerte que los usuarios-lectores pudieran conocer más y mejor las implicaciones de la votación en las urnas y la naturaleza de la discusión entre el gobierno, la sociedad civil y la FARC. También tuvieron el propósito de medir el pulso político entre los interlocutores en La Habana y los alcances de las negociaciones en términos de dinero, impacto en el campo, víctimas y drogas. Estas secciones apuntaban a promover la autonomía de los ciudadanos al momento de dar un voto informado, a partir de la multiplicidad de vías, ángulos y la variedad en los formatos digitales del medio. Es decir, las secciones y el trabajo con herramientas digitales estuvieron a disposición para cumplir los objetivos del periodismo democratizante al que aspira La Silla.

Un ejemplo ilustrativo de la apuesta de La Silla por una participación e interacción es la sección "Quién es quién”. Ésta se adecuó a la coyuntura política para que la audiencia pudiera formarse una visión cada vez más amplia de las dinámicas de poder en el país. En una infografía de las conexiones del poder, cada punto representaba a un personaje y sus relaciones con los poderosos, cuya naturaleza se indicaba por colores: personales, en verde; de trabajo, en morado; rivalidad, en rojo; y alianza, en azul. Los nodos más grandes correspondían a los personajes más poderosos: el Presidente Juan Manuel Santos y el ex Presidente Álvaro Uribe. Con las negociaciones, aparecieron nuevos actores como los miembros del secretariado de la FARC (Figura 3). Los usuarios-lectores podían navegar y cruzar información interactuando con los distintos contenidos para tomar sus decisiones sobre los acuerdos y el rumbo de la sociedad colombiana de cara a la paz. 


\section{Figura 3. Sección "Quién es quién: las conexiones del poder".} Fuente: Equipo de redacción, La Silla Vacía. (2016).

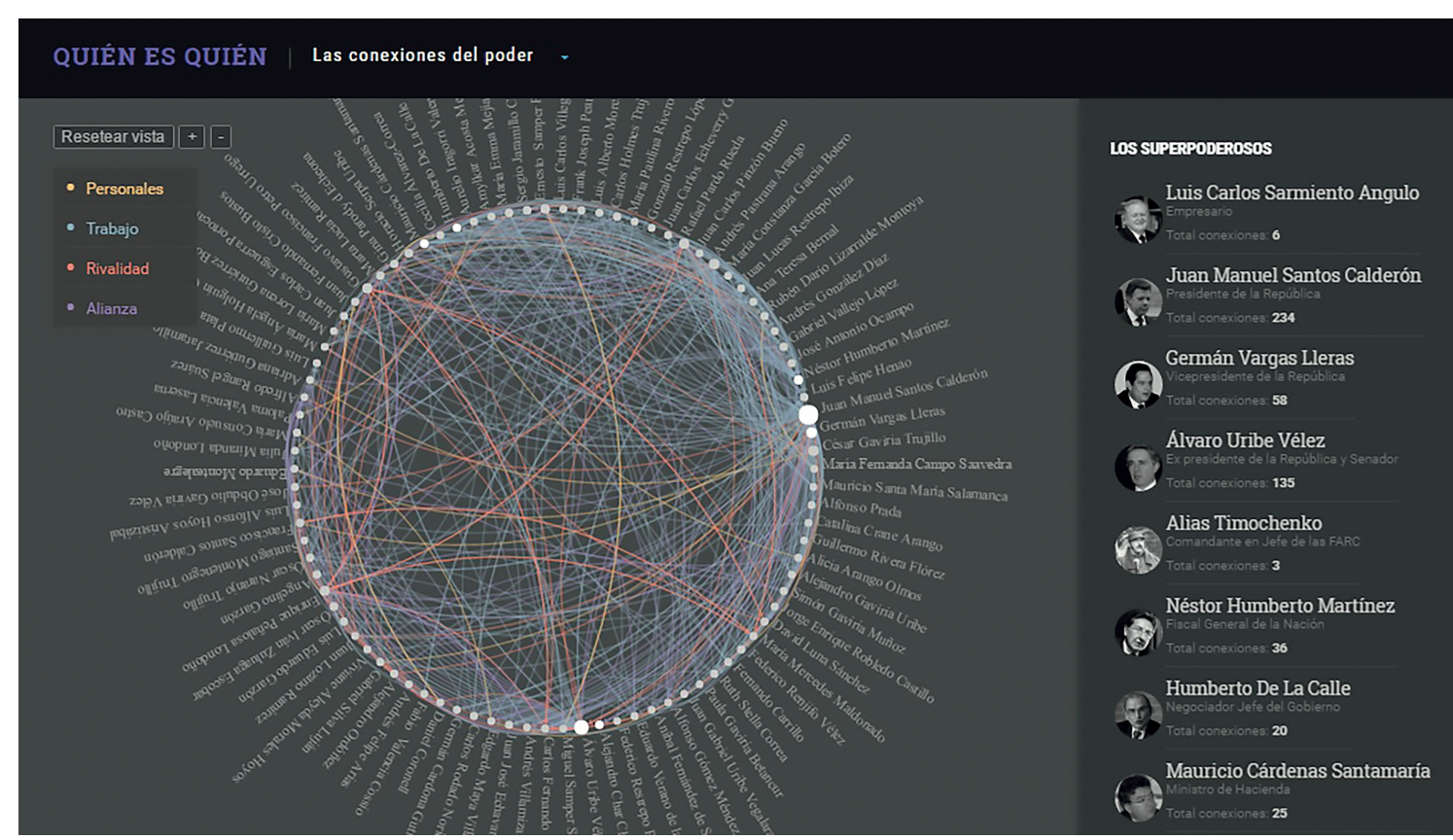

Las herramientas digitales del medio a disposición durante la fase preparatoria del Plebiscito confirmaron lo sugerido por Deuze para el caso de La Silla:

[...] online news has the potential to make the reader/user part of the news experience. Response of the audience is the key[...]Convergence in the context of online journalism [...] is the melting of these traditional media forms -(moving) image, text, sound- in one story told online. [...] the context of the web offers the user the option to choose between the respective elements of the story and offers the journalist the option to 'play around' with these elements: every single story can have a different angle, a different way of telling the story. (Deuze, 1999, p. 377).

Así, con la insistencia en el sostenimiento de una audiencia asidua, con las patas regionales y con narrativas digitales como "Plebiscito" y "Quién es quién”, $L a$
Silla propuso la interacción con las audiencias y entre ellas. El medio exploró lo lúdico, lo visual y la convergencia, usando recursos propios de lo digital, y así logró presentar un contenido sobre el proceso de paz que generó entradas dinámicas al mundo político, el mundo del poder y de los poderosos en el país. La materialidad del espacio digital se convirtió, entonces, en el mejor aliado para trabajar los principios democráticos que identifica La Silla como suyos para aportar a la construcción de sociedad desde el periodismo digital.

\section{Límites informativos frente al Plebiscito}

En la antesala del Plebiscito, La Silla procuró cumplir con sus propios objetivos democratizantes a través de su práctica periodística digital, poniendo sobre la mesa, como se mostró arriba, 
principios alineados con la participación y la inclusión. También tendió a apoyar el SÍ -cosa que confirmó la directora, Juanita León, solo posterior a la votación y al cubrimiento del evento ${ }^{6}$. Todo esto, con resultados inesperados para el medio, de cara a lo ocurrido en las urnas.

En este punto, Van Dijk sigue siendo iluminador. De acuerdo con él, "es necesario considerar de qué manera los fabricantes de la noticia comprenden realmente lo que está pasando y cómo estas comprensiones dan finalmente forma a los textos periodísticos que ellos producen" (Van Dijk, 1990, p. 251). Con esto, se tiene, pues, un primer elemento: el trabajo de disección de los periodistas y su capacidad de dilucidar un asunto de coyuntura y de relevancia colectiva es clave en la producción del relato noticioso. Pero también está un segundo elemento: el papel de la ciudadanía y de otros actores sociales, pues, de acuerdo con Van Dijk (1990), las audiencias que estos componen son fundamentales en tanto que el sentido de la información la hacen en mucho los lectores y, diríamos ahora, los usuarios. Se presenta una relación recíproca, entonces: las audiencias también tejen el entramado de supuestos desde los que parten los mismos medios como $L a$ Silla, tanto como éstos pueden intentar proporcionar nuevos puntos de vista con sus cubrimientos y estrategias de información. Además, en la era digital no sólo se amplió el horizonte de los medios; también se modificó el posicionamiento de las audiencias frente a éstos, de manera que el universo informativo de La Silla fue más dinámico de lo que el mismo medio proyectó.
Mientras La Silla cubría el Plebiscito, éste permanecía confiado en el ejercicio deliberativo y racional como motor de la discusión alrededor de la nación imaginada (y rebatida) a partir de la negociaciones de paz. Igualmente, las audiencias parecían estar, desde la óptica del medio, involucradas en ese mismo ejercico. Y en verdad, tanto para La Silla como para las audiencias, defender la información y el debate crítico fue fundamental dentro de su repertorio: el periodismo lo hacía por convicción en su función democrática. Los ciudadanos lo hacían para reafirmar su capacidad política en clave del derecho a esa información y a ser interlocutores decisivos en la discusión.

Los usuarios-lectores de La Silla, por ejemplo, tienen, según datos del medio que sirven de insumo para sus patrocinadores (instituciones académicas, fundaciones sin ánimo de lucro, entre otras), ingresos y niveles de educación altos. Esto significó para el medio, en el momento del Plebiscito, la firme convicción de que los argumentos periodísticos (la información completa, los análisis políticos) llevarían a votar SÍ, pues con esto se dejaba atrás la historia de más de 60 años de violencia para abrirle la puerta a la equidad, el desarrollo, la paz. Por eso, el medio dispuso de las secciones dirigidas a apoyar esos argumentos periodísticos. Entre esas, junto a las antes mencionadas, hubo una muy reveladora de esa convicción de La Silla: "El poder de los argumentos". Como una usuariacolaboradora de La red de la paz de $L a$ Silla lo presentó, el asunto del Plebiscito giraba en torno a las emociones mucho

6 Esto, en el contexto del conversatorio “iPeriodismo y paz! Entre la auto-crítica y la re-invención”, liderado por Omar Rincón, Fescol, Bogotá, 30 de noviembre de 2016. 
más que a la razón (Araoz, 2016). Esto mismo lo confirmaron las voces autorizadas en el marco de la opinión pública colombiana ("Por qué ganó el No", 2016; Pacheco, 2016). También lo hizo la propia León, quien aseguró que La Silla funcionó en el escenario discursivo del que participaba un número reducido, pero poco compitió con la oleada de emociones de las redes sociales y, sobre todo, de WhatsApp, donde se configuró la alineación para las urnas ${ }^{7}$.

El ejercicio debilerativo, racional, fue un dispositivo pero solo en el plano retórico de la democracia. Allí éste sirvio de soporte para todas las partes, y el medio se adhirió a una práctica periodística conducente a ese ejercicio, fiándose de que hacía eco de lo que para las audiencias eran supuestos a su vez importantes. Con ello, sin embargo, sobrevaloró ingenuamente su poder informativo $\mathrm{y}$, sobre todo, su conocimiento de las audiencias de la era digital, mientras creía que la balanza se inclinaría hacia el Sí, por cuenta de la razón. Por su parte, la ciudadanía, como en otros casos recientes de participación en las urnas, que explica elocuentemente Brooke Gladstone, decidió guiada más por sus inclinaciones y marcos de opinión, que por la consulta de medios potentes y comprometidos o la evaluación disciplinada que hubiera podido llegar a hacer de las noticias (Gladstone, 2017; Hoggett \& Thompson, 2012; Goodwin \& Jasper, 2001).

Si La Silla confió demasiado, sin anticipar las respuestas de la gran mayoría, las audiencias hicieron del supuesto valor compartido de la deliberación ra- cional más un performance mediático que una realidad política. Esto, derivado de su actividad digital competente (o no) y las prácticas que ello conlleva políticamente: la formación de trincheras de opinión que intensifican los propios prejuicios antes que cuestionarlos y la exacerbación de emociones que redundan en discursos de odio, por ejemplo (Gladstone, 2017). La mayoría de los colombianos exigieron información y espacios de interlocución y diálogo en los foros públicos a través de las redes, parados en los derechos ciudadanos democráticos, pero votaron por cuenta de sus sentimientos y no los argumentos.

Con todo, aún es posible afirmar que, como los demás medios, La Silla tiene la facultad de legitimar intereses y de delimitar marcos interpretativos de comprensión (Rincón, et.al., 2002; Martini, 2000) desde sus apuestas periodísticas. Ostenta, pues, la capacidad de intercambio simbólico y la fuerza representacional para establecer dispositivos culturales en los que confluyen antiguas y nuevas formas de expresión, tal y como Rey (1998) lo muestra para los entornos mediáticos. Esto es, La Silla constituye un recurso de micropoder, similar al del periodismo de siempre (Sánchez-Ruíz, 20026), uno que, en términos de una teoría gramsciana renovada, tiene la cualidad de "encausador", productor de realidades: costumbres, identidad y política. Pero, en tanto espacio interdependiente frente a las audiencias (Van Dijk, 1990), y en una era digital de la que beben tanto medios como ciudadanos por igual, hombro a hombro, también está sujeto al

7 Juanita León reconoció la importancia de las emociones en votaciones como esta, en el marco del conversatorio “iPeriodismo y paz! Entre la auto-crítica y la re-invención”, liderado por Omar Rincón, Fescol, Bogotá, 30 de noviembre de 2016. 
conjunto de registros performativos de esas audiencias. Para el momento del Plebiscito, La Silla desconocía estos registros, en virtud no solo de esa superlativa confianza del medio en la deliberación y la racionalidad, sino también, y de manera importante, en virtud de su confianza en la sanción que la ciudadanía misma hacía en redes de la información y el debate como base de participación democrática para ella misma.

\section{Ruta periodística digital después del Plebiscito}

Desde La Silla, la selección de contenidos, la elección de las formas de lenguaje para presentarlos, la interacción con la información, entre otros, fueron fundamentales en la elaboración de una propuesta de orden político $\mathrm{y}$, por lo mismo, de nación, al momento de producir contenidos sobre la paz. Sin embargo, por mucho que se siga refrendando el argumento de los medios como cuarto poder en las sociedades de hoy (Rettberg \& Rincón, 2011), las composiciones periodísticas y los paradigmas políticos de los medios digitales como La Silla parecen recrear conversaciones solo hasta cierto punto compartidas.

Entonces, ¿qué camino es preciso tomar? Después del Plebiscito y "la plebitusa", La Silla ha optado por persistir y seguir cubriendo a los poderosos y ahondar en el análisis político para por lo menos llamar al orden a los poderosos y presionarlos. Esa constancia en su visión periodística es la manera en que el medio ha pensado su papel en lo que Dewey (2001) llamó la redefinición perpetua de la democracia por las sociedades de cada tiempo. Pero, de nuevo, ¿tendría La Silla que implementar nuevos enfoques y ángulos? ¿Debería intentar, así, con variaciones de esos enfoques y ángulos, ser menos racional y más relacional?

El poder, como lo concibe el medio, sigue siendo tema fundamental mientras las estructuras de gobernabilidad actuales sigan vigentes. Desde una visión pragmática, alguien tiene que cubrir esa trasescena política, y eso sostiene la legitimidad de La Silla y su ocupación digital. Así las cosas, los enfoques y ángulos, centrados en el poder institucional, pueden, como lo ha querido el medio después del Plebiscito, mantenerse intactos. Aquí, sin embargo, lo que quizá sí merezca ser re-considerado es aquello que Matt Tullis (2013), en conversación con otros renombrados periodistas, Chris Jones, Thomas Lake y Ben Montgomery, sugirió: el periodismo, como cualquier otro ejercicio de producción de historias, bien puede trabajar - porque lo ha hecho ya en múltiples ocasiones- de manera detallada en la construcción de narrativas complejas, antes ahondando en la planeación de las estructuras de las historias para luego lograr más eficazmente la captura de lugares, tiempos, personajes, a través de la reportería y la síntesis creativas (Tullis, et.al. 2013). Esto podría conectar más a las audiencias con las repercusiones del poder en sus propias vidas, acercándolo a las realidades cotidianas de todos, conformadas por las pasiones $\mathrm{y}$ opiniones en torno a experiencias vitales, todo en la convivencia digital. Es decir, una posible ruta sería el trabajo más detenido en la pre-producción de las historias para que el énfasis en el poder revele la relevancia de éste en el día a día de cualquiera: en suma, configurar y crear historias periodísticas, pero más relacionales. 


\section{Bibliografía}

Abad-Faciolince, Héctor. (2016). Explicar el fracaso: el análisis de Héctor Abad sobre el plebiscito. El Espectador. Recuperado de https://www.elespectador.com/opinion/explicar-el-fracaso-el-analisis-de-hector-abad-sobre-el-articulo-658417

Appelbaum, Nancy. (2003). Muddied Waters: Race, Region and Local History in Colombia, 1846-1948. Durham, Inglaterra: Duke University Press.

Araoz, Ana María. (2016). ¡Deje de argumentar! Este plebiscito será un baile de narrativas y emociones. La Silla Vacía. Recuperado de http://lasillavacia.com/silla-llena/red-de-la-paz/historia/deje-de-argumentar-este-plebiscito-seraun-baile-de-narrativas-y

Avellaר-Bermúdez, Estefanía. (2019). Febrero: 28 días, 19 mujeres asesinadas. Cerosetenta. Recuperado de https://cerosetenta.uniandes.edu.co/febrero-28-dias-18-mujeres-asesinadas/

Bates, Douglas; Maechler, Martin; Bolker, Ben \& Walker, Steve. (2015). Fitting Linear Mixed-Effects Models Using Ime4. Journal of Statistical Software, 67(1), 1-48. D0I: http://dx.doi.org/10.18637/jss.v067.i01

Becerra, Martín, \& Mastrini, Guillermo. (2010). Concentración de los medios de América Latina: Tendencias de un nuevo siglo. Contratexto, 18, 41-64.

Bonilla, Jorge Iván; Cataño, Mónica; Rincón, Omar \& Zuluaga, Jimena. (2012). De las audiencias contemplativas a los productores conectados. Mapa de los estudios y de las tendencias de los ciudadanos mediáticos. Cali, Colombia: Sello Editorial Javeriano.

Castells, Manuel. (2009). Comunicación y poder. Madrid, España: Alianza editorial.

Coronell, Daniel. (2011). Medios de comunicación y gobernabilidad en Colombia. Entre la verdad y la justicia, hay que escoger la verdad. En A. Rettberg y 0. Rincón (Comps.), Medios, Democracia y Poder (pp. 159-173). Bogotá, Colombia: Ediciones Uniandes.

Dewey, John. (2001). Democracy and Education. Recuperado de htttp://www.naturalthinker.net/tr//texts/Dewey, John/Dewey,_John_-_Democracy_And_Education.pdf

Deuze, Mark. (1999). Journalism and the Web: An Analysis of Skills and Standards in an Online Environment. Gazette (Leiden, Netherlands), 61(5), 373-390. D0I: https://doi.org/10.1177/0016549299061005002

Fogel, J. F. (2007). Veinte apuntes sobre el ciberLeviatán. Letras Libres. Recuperado de https://www.letraslibres.com/mexico-espana/veinte-apuntes-sobre-el-ciberleviatan

Gladstone, Brooke. (2017). The Trouble with Reality. A Rumination on Moral Panic in Our Time. Nueva York, NY: Workman.

Goodwin, Jeff \& Jasper, James. (2001). Passionate Politics: Emotions and Social Movements. Chicago, IL: The University of Chicago Press.

Hoggett, Paul \& Thompson, Simon. (2012). Politics and the Emotions: The Affective Turn in Contemporary Political Studies. Nueva York, NY: Contunuum.

Karl, Robert. (2017). Forgotten Peace: Reform, Violence and the making of Contemporary Colombia. Oakland, CA: University of California Press.

León, Juanita, \& Lozano, Olga. (2013). La Silla Vacía, un modelo del periodismo del futuro. Bogotá, Colombia: eCiseros Libros.

McLuhan, Marshall. (1996). Comprender los medios de comunicación. Barcelona, España: Paidós.

Martini, Stella. (2000). Periodismo, noticia y noticiabilidad. Buenos Aires, Argentina: Norma. 
Martínez, María Paula, \& Zuluaga, Jimena. (2012). Mapping Digital Media: Colombia. Reino Unido: Open Society Foundations. Moreno, D., Viana, N., González, M., Fernández, P., Chamorro, C. F., Dada, C., Gorriti, G., León, J., Rodríguez-Pellecer, M., y Pasquini, G. (20 de junio del 2013).

Morelo, Gina; Castrillón, Gloria \& Behar, Olga. (2014). Pistas para narrar la paz: periodismo en el posconflicto. Bogotá, Colombia: Fundación Konrad Adenauer -KAS- Colombia y Consejo de Redacción.

Nace Aliados, red de medios digitales de América Latina. Animal Político. Recuperado de: http://www.animalpolitico.com/2013/06/nace-la-red-de-medios-digitales-independientes/

Nace nuestra primera pata regional: La Silla Caribe ¡Salud! (3 de mayo del 2015). La Silla Vacía. Recuperado de http://lasillavacia.com/historia/nace-nuestra-primera-pata-regional-la-silla-caribe-salud-50171

Pacheco, Daniel. (2016). La paz de todos. El Espectador. Recuperado de https://www.elespectador.com/opinion/paz-detodos

Piscitelli, Alejandro. (2005). La imprenta del siglo XXI. Barcelona, España: Gedisa.

Por qué ganó el No. (2016). Semana. Recuperado de https://www.semana.com/nacion/articulo/por-que-gano-el-no-enel-plebiscito-por-la-paz-2016/496636

R Development Core Team (2008). R: A language and environment for statistical computing. R Foundation for Statistical Computing [Software]. Recuperado de http://www.R-project.org

Rettberg, Angelika., \& Rincón, Omar. (Comps.). (2011). Medios, democracia y poder. Una mirada comparada desde Colombia, Ecuador, Venezuela y Argentina. Bogotá, Colombia: Ediciones Uniandes.

Rey, Germán. (1998). Balsas y medusas. Visibilidad comunicativa y narrativas políticas. Bogotá, Colombia: Prisma asociados.

Rincón, Omar; García, Sandra \& Zuluaga, Jimena. (2002). La nación y los medios. Bogotá, Colombia: Ministerio de cultura.

Roldán, Mary. (2002). Blood and Fire: la violencia in Antioquia, Colombia, 1946-1953. Durham, Inglaterra: Duke University Press.

Sánchez-Ruíz, Enrique. (2006). Medios de comunicación y democracia. Bogotá, Colombia: Norma.

Scolari, Carlos. (2008): Hipermediaciones: elementos para una teoría de la comunicación digital interactiva. Barcelona, España: Gedisa.

Schiffrin, Anya, \& Zuckerman, Ethan. (2015). Can We Measure Media Impact? Stanford Social Innovation Review, 13 (4). Recuperado de https://ssir.org/articles/entry/can_we_measure_media_impact_surveying_the_field

Tullis, Matt; Jones, Chris; Lake, Thomas \& Montgomery, Ben. (2013). Journalism Equals Facts While Creative Nonfiction Equals Truth? Maybe it's Not that Simple. Creative Nonfiction, 47, 64-71.

Van 226 líderes asesinados en el país en lo que va del año. (2018). El Tiempo. Recuperado de https://www.eltiempo.com/colombia/otras-ciudades/lideres-sociales-asesinados-en-colombia-entre-enero-y-noviembre-del-2018-296924

Van Dijk, T. (1990). La noticia como discurso. Barcelona, España: Paidós Comunicación. 